\title{
Synthesis of 2-Substituted Benzimidazoles and 1,5-Disubstituted Benzodiazepines on Alumina and Zirconia Catalysts
}

\author{
M. REKHA ${ }^{1}$, A. HAMZA ${ }^{1}$, B. R. VENUGOPAL ${ }^{2}$, N. NAGARAJU ${ }^{1, *}$ \\ ${ }^{1}$ Catalysis Research Laboratory, St. Joseph's College and Research Centre, 39 Lalbagh Road, Shanthinagar, Bangalore 560027 , India \\ ${ }^{2}$ Laboratory of Chemistry and Electrochemistry of Surfaces, Facultés Universitaires Notre-Dame de la Paix,
} Rue de Bruxelles, 61, B-5000, Namur, Belgium

\begin{abstract}
In this study, alumina, zirconia, manganese oxide/alumina, and manganese oxide/zirconia have been investigated for their catalytic activity in the condensation reaction between $o$-phenylenediamine and an aldehyde or a ketone to synthesise 2-substituted benzimidazoles and 1,5-disubstituted benzodiazepines respectively. Surface area, surface acidity, and morphology of the catalysts have been analysed and correlated with their catalytic activity. The isolated yields of 2-substituted benzimidazoles and 1,5-disubstituted benzodiazepines are in the range of $30 \%$ to $95 \%$. A good correlation between the amount of surface acid sites as well as the surface morphology of the catalysts and the catalytic activity has been observed. This method has been found to be simple and economical. The solid supports could be regenerated and reused without much loss in their activity. Further, the solid supports have been also found to be effective as general catalysts in the condensation of $o$-phenylenediamine with other substituted aldehydes and ketones.
\end{abstract}

Key words: 2-substituted benzimidazoles; 1,5-disubstituted benzodiazepines; manganese oxide; alumina; zirconia

CLC number: $\mathrm{O} 643$

Document code: A

Received 22 September 2011. Accepted 7 November 2011.

*Corresponding author.Tel: +91-9886765750; Fax: +91-8022245831; E-mail: nagarajun@yahoo.com

This work was supported by the UGC, New Delhi.

English edition available online at Elsevier ScienceDirect (http://www.sciencedirect.com/science/journal/18722067).

For several decades there has been a concern for improving the chemical processes in industry, with regard to environmental and health related issues, which would also eventually reduce chemical waste. Catalytic activation of substrates under heterogeneous conditions using solid acids and bases [1,2] as catalysts or catalyst supports has been identified as one of the important ways to make the given process environmentally benign and efficient. Thus over the years a lot of research has been focused on the development of greener processes [3]. Benzimidazole derivates exhibit various biological and pharmaceutical properties [4-7]. Recently it has been found that benzimidazole derivatives are useful as fluorescent chemosensors for $\mathrm{Cu}^{2+}$ [8]. Benzodiazepine and their derivates are also interesting class of bioactive compounds widely used in therapeutics [9] as anti-convulsant, analgesics, anti-anxiety drugs, sedatives, anti-depressants, and hypnotics [10-12]. One of the methods commonly reported by several groups for the synthesis of benzimidazoles and benzodiazepines is the condensation reaction between $o$-phenylenediamine (OPDA) and an aldehyde [13-15] or a ketone [16-19], respectively.

Catalytic activities of different Lewis acids have been investigated in the synthesis of benzimidazoles and benzodiazepines by different groups highlighting the advantages of their protocol over the other methods. However, to the best of our knowledge no attempt has been made to correlate the surface properties of the catalysts and their catalytic activity in the condensation of aldehydes/ketones with OPDA to synthesise benzimidazoles and benzodiazepines.

Metal oxides and supported metal oxides are known to possess surface acidity and/or basicity and activate a number of industrially important organic transformations [20,21]. Accordingly the present investigation focuses on the preparation, characterization, and catalytic applications of $\mathrm{Al}_{2} \mathrm{O}_{3}, \mathrm{ZrO}_{2}$, Manganese oxide/ $\mathrm{Al}_{2} \mathrm{O}_{3}$ and Manganese oxide $/ \mathrm{ZrO}_{2}$. A correlation between the amount of surface acid sites, surface morphology, and the catalytic activity is described.

\section{Experimental}

\subsection{Preparation of the catalyst}

Catalysts containing $5 \%$ of manganese oxide on $\mathrm{Al}_{2} \mathrm{O}_{3}$ and $\mathrm{ZrO}_{2}$ were prepared by precipitation method. A calculated quantity of manganese sulphate was dissolved in 500 $\mathrm{ml}$ of distilled water. To this solution, a required amount of $\mathrm{Al}(\mathrm{OH})_{3}$ or $\mathrm{Zr}(\mathrm{OH})_{4}$ powder was added in small portions 
while the solution was being stirred (molar ratio of $\mathrm{Mn}: \mathrm{Al}=$ 0.05:0.95). The mixture was heated to $80{ }^{\circ} \mathrm{C}$ and $28 \% \mathrm{NH}_{3}$ solution was added drop-wise to precipitate manganese as its hydroxide $(\mathrm{pH}=9)$. A thick brown precipitate thus obtained was digested for $4 \mathrm{~h}$ on a water bath, separated by filtration, washed with distilled water, and dried in a hot air oven at $120{ }^{\circ} \mathrm{C}$ for $12 \mathrm{~h}$ and then calcined in a furnace at $450{ }^{\circ} \mathrm{C}$ for $5 \mathrm{~h} . \mathrm{Al}_{2} \mathrm{O}_{3}$ and $\mathrm{ZrO}_{2}$ catalysts without manganese oxide were obtained by drying the commercial $\mathrm{Al}(\mathrm{OH})_{3}$ or $\mathrm{Zr}(\mathrm{OH})_{4}$ at $120{ }^{\circ} \mathrm{C}$ followed by calcination at $450{ }^{\circ} \mathrm{C}$ for $5 \mathrm{~h}$. These catalysts are denoted as $\mathrm{Al}_{2} \mathrm{O}_{3}-120, \mathrm{MnAl}_{2} \mathrm{O}_{3}-120$, $\mathrm{Al}_{2} \mathrm{O}_{3}-450, \mathrm{MnAl}_{2} \mathrm{O}_{3}-120, \mathrm{ZrO}_{2}-120, \mathrm{MnZrO}_{2}-120, \mathrm{ZrO}_{2}-$ 450, and $\mathrm{MnZrO}_{2}-450$.

\subsection{Characterization of the catalyst}

BET surface area of the catalysts was determined from $\mathrm{N}_{2}$ adsorption data acquired on a Micromeritics TriStar 3000 instrument. Powder X-ray diffraction (XRD) patterns were recorded on a Panalytical Xpert pro X-ray diffractometer using $\mathrm{Cu} K_{\alpha}$ radiation $(\lambda=0.154 \mathrm{~nm})$ in the $2 \theta$ range of $5^{\circ}-70^{\circ}$ at $40 \mathrm{kV}$ and at a scanning rate of $2^{\circ} / \mathrm{min}$. The amounts of surface acid sites of the catalysts were determined by $N$-butylamine titration method. The surface morphology of the materials were studied by field-emission scanning electron microscopy (FE-SEM) using JEOL JSM-7500F microscope operating at $20 \mathrm{kV}$ at a working distance of $8 \mathrm{~mm}$. The particle size and distribution of the materials were studied by low resolution transmission electron microscopy (TEM) using a TECNAI 10 PHILIPS microscope. Prior to the analysis, the samples were dispersed in ethanol and a drop of the suspension was deposited on a holey carbon-coated copper grid.

\subsection{Characterization of the reaction product}

Infrared spectra of the products were recorded from a Nicolet Model Impact 400D FT-IR spectrometer with 4 $\mathrm{cm}^{-1}$ resolution. Sample pellets were made by pressing a mixture of the sample with $\mathrm{KBr}$ in the required ratio. The mass spectra of the filtrate were recorded on GC-MS Shimadzu QP 5000, GC-17A. ${ }^{1} \mathrm{H}$ NMR spectrum was obtained in DMSO solution at $300 \mathrm{MHz}$ using Bruker Avance NMR spectrometers. Spectrum is referenced to transcranial magnetic stimulation (TMS).

\subsection{Catalytic activity study}

Catalytic activity of the catalysts, dried at $120{ }^{\circ} \mathrm{C}$ and calcined at $450{ }^{\circ} \mathrm{C}$, was investigated in the condensation reaction between OPDA and benzaldehyde or acetophenone (Scheme 1). This is used as a model reaction. In a typical procedure a mixture of OPDA ( $1 \mathrm{mmol})$, benzaldehyde (1 $\mathrm{mmol}$ ) or acetophenone (2.2 $\mathrm{mmol})$, ethanol (5 ml), and the catalyst $(0.2 \mathrm{~g})$ taken in a $100 \mathrm{ml}$ RB flask was heated to 80 ${ }^{\circ} \mathrm{C}$. The progress of the reaction was monitored periodically by analysing the reaction mixture by thin layer chromatography using a mixture of petroleum ether and ethyl acetate in 8:2 ratio. After completion of the reaction, the reaction mixture was diluted with $10 \mathrm{ml}$ of ethanol and filtered to recover the solid catalyst. The filtrate was poured into a beaker containing crushed ice. The solid product was separated and purified by column chromatography using silica gel [100-200 mesh] with petroleum ether and ethyl acetate as solvent. The products were further analyzed by IR, ${ }^{1} \mathrm{H}$ NMR, and GC-MS techniques.

\section{Results and discussion}

\subsection{Catalyst characterization}

\subsubsection{BET surface area and acidity}

The quantitative data on the BET surface area and amount of surface acid sites of the catalysts are given in the Table 1.

The surface acidities of alumina catalysts followed the order of $\mathrm{MnAl}_{2} \mathrm{O}_{3}-450>\mathrm{Al}_{2} \mathrm{O}_{3}-450>\mathrm{MnAl}_{2} \mathrm{O}_{3}-120>$ $\mathrm{Al}_{2} \mathrm{O}_{3}-120$. For the zirconia catalysts, the surface acidities are $\mathrm{MnZrO}_{2}-450>\mathrm{MnZrO}_{2}-120>\mathrm{ZrO}_{2}-450>\mathrm{ZrO}_{2}-120$.

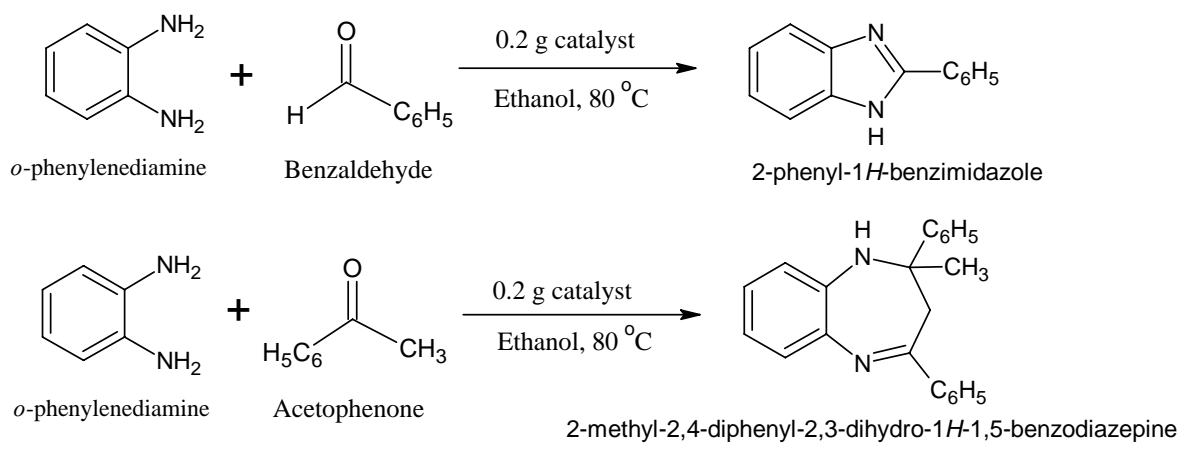

Scheme 1. The condensation reaction between OPDA and benzaldehyde or acetophenone. 
Table 1 Specific surface area, amount of surface acid sites in alumina and zirconia catalysts, and their activity in the synthesis of benzimidazole and benzodiazepines

\begin{tabular}{|c|c|c|c|c|}
\hline \multirow{2}{*}{ Catalyst } & \multirow{2}{*}{$\begin{array}{c}\text { Specific surface area } \\
\left(\mathrm{m}^{2} / \mathrm{g}\right)\end{array}$} & \multirow{2}{*}{$\begin{array}{c}\text { Surface acidity } \\
(\mathrm{mmol} / \mathrm{g})\end{array}$} & \multicolumn{2}{|c|}{ Isolated yield (\%) } \\
\hline & & & Benzimidazole & Benzodiazepine \\
\hline $\mathrm{Al}_{2} \mathrm{O}_{3}-120$ & 1.38 & 0.75 & 30 & 30 \\
\hline $\mathrm{MnAl}_{2} \mathrm{O}_{3}-120$ & 3.13 & 1.00 & 67 & 60 \\
\hline $\mathrm{Al}_{2} \mathrm{O}_{3}-450$ & 262.81 & 1.01 & 52 & 35 \\
\hline $\mathrm{MnAl}_{2} \mathrm{O}_{3}-450$ & 209.67 & 1.25 & 90 & 85 \\
\hline $\mathrm{ZrO}_{2}-120$ & 174.26 & 0.50 & 34 & 47 \\
\hline $\mathrm{MnZrO}_{2}-120$ & 154.90 & 1.50 & 70 & 74 \\
\hline $\mathrm{ZrO}_{2}-450$ & 61.39 & 1.25 & 65 & 70 \\
\hline $\mathrm{MnZrO}_{2}-450$ & 92.37 & 2.25 & 95 & 93 \\
\hline
\end{tabular}

From the above alumina and zirconia catalysts, $\mathrm{MnZrO}_{2}-450$ catalyst showed a higher amount of surface acid sites. The surface area of alumina catalysts followed the order of $\mathrm{Al}_{2} \mathrm{O}_{3}-450>\mathrm{MnAl}_{2} \mathrm{O}_{3}-450>\mathrm{MnAl}_{2} \mathrm{O}_{3}-120>$ $\mathrm{Al}_{2} \mathrm{O}_{3}-120$. For the zirconia catalysts, the surface area are $\mathrm{ZrO}_{2}-120>\mathrm{MnZrO}_{2}-120>\mathrm{MnZrO}_{2}-450>\mathrm{ZrO}_{2}-450$. Surface acidity of alumina catalysts is less than that of zirconia catalysts. Calcination increased the surface acidity more in the case of zirconia than alumina catalysts. $\mathrm{MnZrO}_{2}-450$ catalyst showed the highest surface acidity of all the catalysts. On calcination the surface area of alumina catalysts increased significantly whereas it decreased in the case of zirconia catalysts. $\mathrm{MnAl}_{2} \mathrm{O}_{3}-450$ catalyst showed the highest surface area.

\subsubsection{XRD results}

XRD patterns of the catalysts are shown in Fig. 1. It is observed that on calcinations, crystalline nature of alumina catalysts decreased whereas zirconia sample becomes more crystalline. This observation clearly accounts for the variation in the surface area of the respective samples upon calcination as discussed previously. The highly crystalline XRD pattern of uncalcined $\mathrm{Al}_{2} \mathrm{O}_{3}$ corresponds to the gibbsite phase [22], however the crystallinity of the catalyst decreased on calcination with the formation of boehmite phase [23] (Fig. 1(a)). When manganese oxide is deposited on alumina, the characteristic Hausmannite, $\mathrm{Mn}_{3} \mathrm{O}_{4}$ phase along with the Boehmite phase of alumina was observed which is not observed in $\mathrm{MnAl}_{2} \mathrm{O}_{3}-120$ catalyst. The XRD patterns of $\mathrm{ZrO}_{2}-120$ and $\mathrm{MnZrO}_{2}-120$ shows no distinct peaks indicating the amorphous nature of the catalysts (Fig. 1(b)). On calcination the crystallinity of both the catalysts has increased. In the case of $\mathrm{ZrO}_{2}-450$, majority of the $\mathrm{ZrO}_{2}$ is crystallized into tetragonal phase [24] with small amount of monoclinic phase [25]. However pure tetragonal phase of $\mathrm{ZrO}_{2}$ is formed in the case of $\mathrm{MnZrO}_{2}-450$ due to phase transition of stable monoclinic to tetragonal phase transfer is observed on manganese oxide deposition and calcinations at

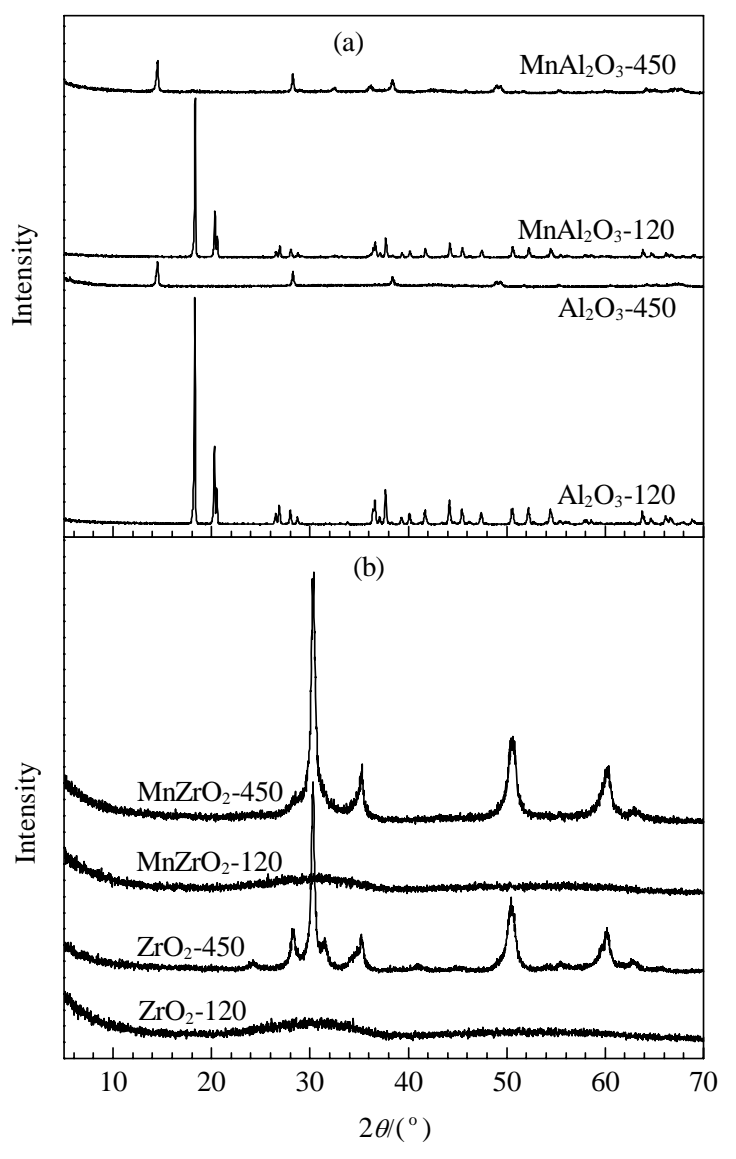

Fig. 1. XRD patterns of alumina (a) and zirconia (b) based catalysts both calcined and uncalcined samples.

$450{ }^{\circ} \mathrm{C}$. It is also noteworthy that upon deposition of manganese oxide on zirconia and calcined at $450{ }^{\circ} \mathrm{C}$, no diffraction peaks corresponding to any manganese oxide phases have appeared and catalytically active tetragonal phase is stabilised.

\subsubsection{SEM and TEM image}

SEM and TEM images of a few representative catalysts are shown in the Fig. 2. It is interesting to note that the 

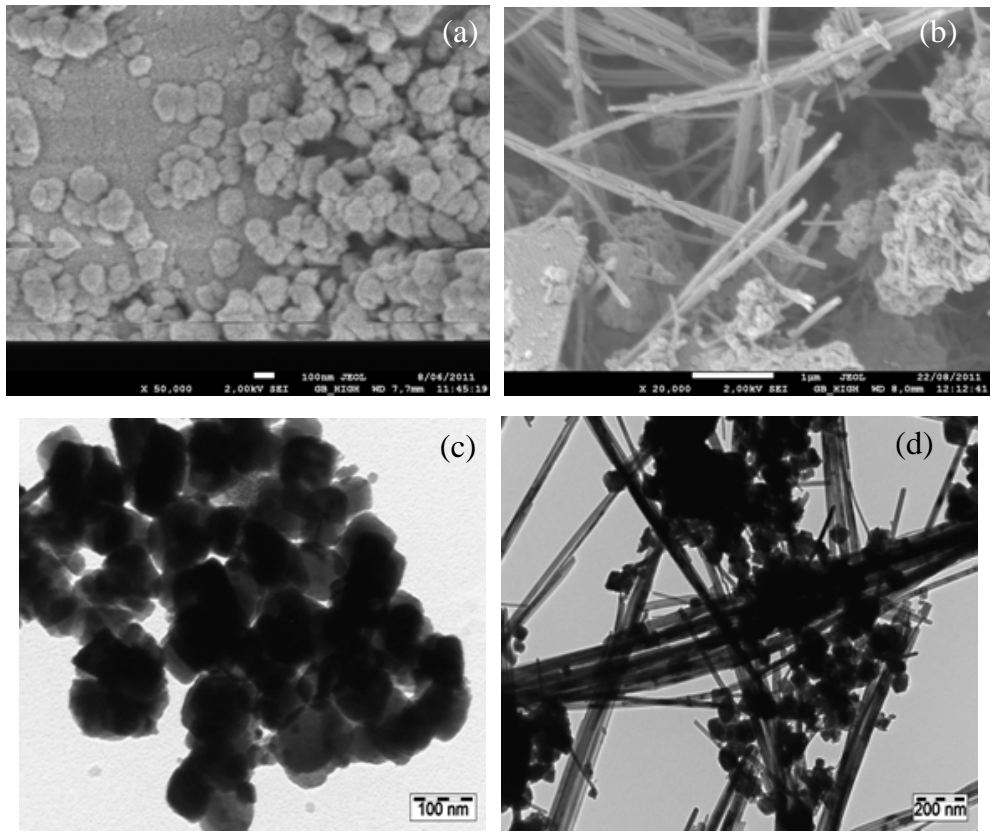

Fig. 2. SEM images of $\mathrm{MnAl}_{2} \mathrm{O}_{3}-450$ (a) and $\mathrm{MnZrO}_{2}-450$ (b) catalysts and TEM images of $\mathrm{MnAl}_{2} \mathrm{O}_{3}-450$ (c) and $\mathrm{MnZrO}_{2}-450$ (d) catalysts.

morphology of the alumina catalysts is distinctly different from those of zirconia catalysts. Samples of zirconia exhibited tubular/needle like shapes with a thickness approximately $30 \mathrm{~nm}$, decorated with manganese oxide particles.

\subsection{Catalytic activity study}

The percentage yields of the isolated product in the condensation reaction between OPDA and benzaldehyde/acetophenone conducted in the presence of solid supports are given in the Table 1 . It is to be noted that the OPDA conversion in the absence of a solid support was low. However, in the presence of $\mathrm{Al}_{2} \mathrm{O}_{3}, \mathrm{ZrO}_{2}$, manganese oxide $/ \mathrm{Al}_{2} \mathrm{O}_{3}$, and manganese oxide/ $\mathrm{ZrO}_{2}$ catalysts improved the yields. The yield of the isolated product was in the range $30 \%$ to $95 \%$. Pure Alumina was found to be less active than pure zirconia. $\mathrm{MnZrO}_{2}-450$ catalyst showed highest catalytic activity than other samples (alumina and zirconia based samples). It is interesting to note that a good correlation between the amount of the acid site and the catalytic activity is observed. Thus, it may be inferred that the condensation reaction between OPDA and an aldehyde/ketone is activated by the surface acidity of the solid catalysts. Further, taking into account of the variation of other textural properties of the catalyst on calcinations and incorporation of manganese oxide, it is worthwhile to mention here that synergistic effects of the following parameters contribute to the overall increase in the catalytic activity of the solid catalysts: (1) enhancement of the intrinsic surface acid sites concentration of the supports on calcination; (2) contribu- tion to the additional acidity by the presence of manganese oxide on alumina and zirconia; (3) stabilisation of catalytically active tetragonal phase of zirconia on calcination in the presence of manganese oxide.

It may be noted here that the boehmite phase of alumina and tetragonal phase of zirconia that are formed upon calcination are catalytically active for this condensation reaction.

It is evident from the results presented in Table 1 , that $5 \% \mathrm{MnZrO}_{2}-450$ showed the best results in terms of OPDA conversion. In order to evaluate the effects of the solvent, reaction temperature, and amount of catalyst on the product yield, the following optimisation reactions were conducted using this catalyst.

\subsubsection{Effect of solvent}

The isolated yields of the reaction products in the presence of different solvents are shown in Fig. 3. The yield was high even in the absence of any solvent but only at high temperatures. The high boiling solvents DMSO and DMF not only resulted in lower yield but also presented handling problems. Further, isolation of the products was found to be tedious when water was used as the solvent. Methanol was not preferred as it is not safe and is not green. Acetonitrile and chloroform also resulted in lower yields. Ethanol was found to be the best solvent for this reaction based on its low cost, easy work-up of the reaction mixture, and good yield of the products. Hence for further studies in synthesis of substituted benzimidazoles and benzodiazepines ethanol is used as a solvent. 


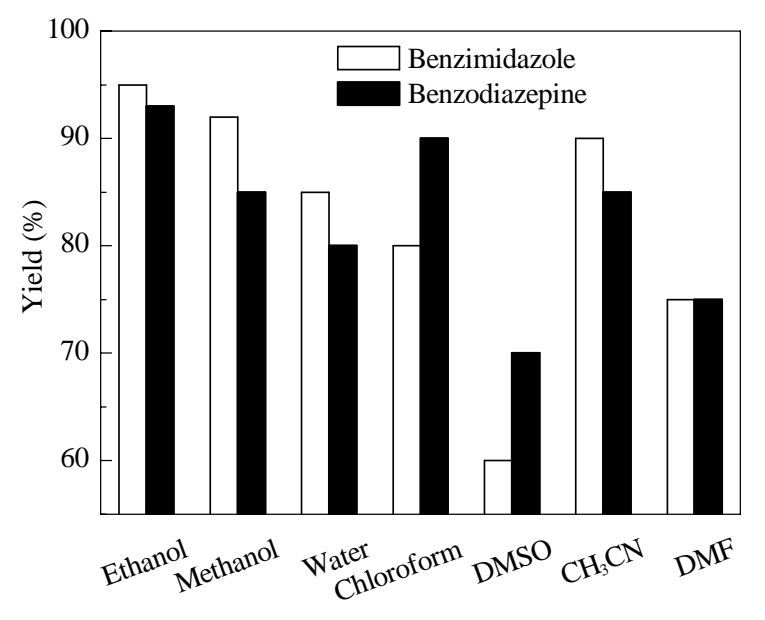

Fig. 3. Effect of solvents on the activity of $\mathrm{MnZrO}_{2}-450$ catalyst.

\subsubsection{Effect of reaction temperature}

The results of the experiments conducted at different temperatures are shown in Fig. 4. When the reaction was conducted at room temperature the yield was only $25 \%$ to $30 \%$. However the conversion of OPDA was found to increase with good selectivity with an increase in the temperature up to $80{ }^{\circ} \mathrm{C}$, above which the conversion of OPDA remained constant while the selectivity towards the expected product also decreased.

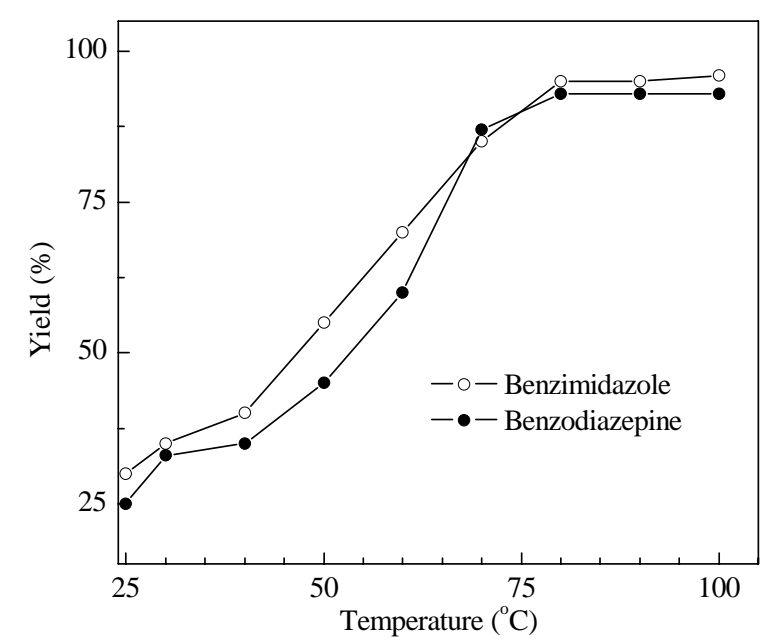

Fig. 4. Effect of temperature on the activity of $\mathrm{MnZrO}_{2}-450$ catalyst.

\subsubsection{Amount and reusability of the catalyst}

The condensation reactions were conducted using ethanol as the solvent at $80{ }^{\circ} \mathrm{C}$ and different amounts of $5 \%$ $\mathrm{MnZrO}_{2}-450$ catalyst in the range 0.05 to $1 \mathrm{~g}$. The best yield of the reaction product was obtained with $0.2 \mathrm{~g}$ of the catalyst. Higher amounts of the catalyst did not improve the yield. The catalyst could be easily recovered by simple fil- tration of the reaction mixture, followed by washing with acetone and drying in oven at $110{ }^{\circ} \mathrm{C}$ for $2 \mathrm{~h}$. Recovery of the catalytic activity of the zirconia based catalysts was better than alumina based catalysts. Zirconia catalysts could be reused upto 5 times without any significant loss in catalyst efficiency (Table 2).

Table 2 Recovery of $\mathrm{MnZrO}_{2}-450$ catalyst in the synthesis of substituted benzimidazole and benzodiazepine

\begin{tabular}{ccc}
\hline \multirow{2}{*}{ Cycle } & \multicolumn{2}{c}{ Isolated yield (\%) $^{$\cline { 2 - 3 }$}$} \\
\cline { 2 - 3 } Benzimidazole $^{\mathrm{a}}$ & Benzodiazepine $^{\mathrm{b}}$ \\
\hline 2 & 95 & 93 \\
3 & 90 & 85 \\
4 & 88 & 83 \\
& 87 & 75 \\
\hline
\end{tabular}

a Reaction conditions: OPDA (1 mmol), aldehyde (1 mmol), 0.2 g $\mathrm{MnZrO}_{2}-450$ catalyst, $5 \mathrm{ml}$ ethanol.

${ }^{\mathrm{b}}$ Reaction conditions: OPDA (1 mmol), ketone (2.2 mmol), $0.2 \mathrm{~g}$ $\mathrm{MnZrO}_{2}-450$ catalyst, $5 \mathrm{ml}$ ethanol.

\subsubsection{Generality of the catalytic activity of the catalysts}

The activity of our catalyst was further investigated for its general application in the condensation reaction of OPDA with other substituted aldehydes and ketones. All the reactions were conducted with $5 \% \mathrm{MnZrO}_{2}-450$ catalyst, using ethanol as the solvent under refluxing conditions. The results in terms of the isolated yield of the expected product with various substituted aldehydes and ketones are presented in the Tables 3 and 4, respectively. It is noteworthy that an excellent yield of the expected product could be obtained with in $1-2 \mathrm{~h}$ of the reaction. All the isolated products were analysed by their MP, IR, GC-MS, and ${ }^{1}$ HNMR techniques. The condensation of OPDA with aldehydes was more efficient than the ketones in terms of the duration of the reaction. Thus it may be concluded that manganese oxide supported on zirconia may be used as general catalyst to activate the condensation reaction described in this paper.

The spectral data of some representative products are given below.

Entry 1 in Table 3. 2-Phenyl-1H-benzimidazole: pale yellow solid. mp: 293-296 ${ }^{\circ} \mathrm{C}$; IR (KBr) 3042, 1440, 1403, 1271, $971 \mathrm{~cm}^{-1}$. MS: $m / z=193\left(\mathrm{M}^{+}\right) .{ }^{1} \mathrm{H}$ NMR $(300 \mathrm{~Hz}$, DMSO): $\delta 7.22$ (m, 2H), 7.48 (m, 5H), 7.58 (s, IH), 8.04 (d, $2 \mathrm{H}, J=1.6 \mathrm{~Hz}$ ).

Entry 5 in Table 3. 2-(4-Chlorophenyl)-1H-benzimidazole: pale yellow solid. mp: 291-293 ${ }^{\circ} \mathrm{C}$; IR (KBr) 3039, 1449, 1400, 1275, $961 \mathrm{~cm}^{-1}$. MS: $m / z=228\left(\mathrm{M}^{+}\right) .{ }^{1} \mathrm{H}$ NMR (300 Hz, DMSO): $\delta 7.10$ (m, 2H), 7.6 (d, 2H, $J=8.4 \mathrm{~Hz}$ ), 7.3 (m, 2H), 8.2 (d, 2H, $J=8.7 \mathrm{~Hz}$ ), 8.04 (d, 2H, $J=1.6$ $\mathrm{Hz})$. 
Table 3 Condensation of OPDA with various substituted aldehydes in presence of $\mathrm{MnZrO}_{2}-450$ catalyst and ethanol as a solvent

\begin{tabular}{|c|c|c|c|c|c|}
\hline Entry & Diamine & Aldehyde & Product & Time (min) & Yield (\%) \\
\hline 1 & & benzaldehyde & & 60 & 95 \\
\hline 2 & & 2-methyl-butyraldehyde & & 90 & 87 \\
\hline 3 & & 2-ethyl-butyraldehyde & & 90 & 90 \\
\hline 4 & & 4-fluoro-benzaldehyde & & 45 & 91 \\
\hline 5 & & 4-chloro-benzaldehyde & & 45 & 85 \\
\hline 6 & & cinnamic aldehyde & & 35 & 92 \\
\hline 7 & & anisaldehyde & & 45 & 93 \\
\hline 8 & & 4-cyanobenzaldehyde & & 45 & 90 \\
\hline
\end{tabular}

Table 4 Condensation of OPDA with various substituted ketones in presence of $\mathrm{MnZrO}_{2}-450$ catalyst and ethanol as a solvent

\begin{tabular}{|c|c|c|c|c|c|}
\hline Entry & Diamine & Ketone & Product & Time (min) & Yield (\%) \\
\hline 1 & & acetone & & 45 & 93 \\
\hline 2 & & 2-butanone & & 60 & 87 \\
\hline 3 & & 3-pentanone & & 90 & 92 \\
\hline 4 & & cyclopentanone & & 90 & 85 \\
\hline 5 & & cyclohexanone & & 90 & 85 \\
\hline 6 & & cycloheptanone & & 90 & 92 \\
\hline 7 & & acetophenone & & 60 & 90 \\
\hline 8. & & 4-nitro-acetophenone & & 60 & 87 \\
\hline
\end{tabular}

Entry 7 in Table 3. 2-(4-Methoxyphenyl)-1H-benzimidazole: yellow solid. mp: 225-226 ${ }^{\circ} \mathrm{C}$; IR (KBr) 3478, 2985, 1625, 1537, 1341, 1127, 1038, $835 \mathrm{~cm}^{-1}$. MS: $\mathrm{m} / \mathrm{z}=$ 224(M $\mathrm{M}^{+}$). ${ }^{1} \mathrm{H}$ NMR (300 Hz, DMSO): $\delta$ 8.00-8.08 (m, 2H), 7.20-7.60 (m, 6H), 3.52 (m, 3H).

Entry 1 in Table 4. 2-Methyl-2,4-diphenyl-2,3-dihydro1H-1,5-benzodiazepine: yellow solid. mp: $150-152{ }^{\circ} \mathrm{C}$. IR (KBr) 3351, 1647, $1593 \mathrm{~cm}^{-1}$. MS: $m / z=188\left(\mathrm{M}^{+}\right) .{ }^{1} \mathrm{H}$ NMR (300 Hz, DMSO): $\delta 1.73$ (s, 3H), 2.95 (d, 2H, $J=$
$0.17 \mathrm{~Hz}$ ), 3.12 (d, 2H, $J=0.17 \mathrm{~Hz}), 3.38$ (br, 1H), 6.80-7.72 (m, $14 \mathrm{H})$.

Entry 3 in Table 4. 2,2,4,-Triethyl-3-methyl-2,3-dihydro-1H-1,5-benzodiazepine: yellow solid. mp: 143-145 ${ }^{\circ} \mathrm{C}$; IR (KBr) 3324, 1637, $1582 \mathrm{~cm}^{-1}$. MS: $m / z=245\left(\mathrm{M}^{+}\right) .{ }^{1} \mathrm{H}$ NMR (300 Hz, DMSO): $\delta$ 0.78-1.75 (m, 14H), 2.63 (m, 2H), 3.13 (q, 1H, $J=7.0 \mathrm{~Hz}$ ), 3.69 (br, 1H), 6.71-7.48 (m, 4H).

Entry 7 in Table 4. 2-Methyl-2,4-diphenyl-2-3-dihy- 
Table 5 Comparison of catalytic activity of $\mathrm{MnZrO}_{2}-450$ catalyst with other reported catalysts

\begin{tabular}{|c|c|c|c|c|c|}
\hline Catalyst & Solvent & Reaction time (h) & Benzimidazole yield (\%) & Benzodiazepine yield (\%) & Reference \\
\hline $5 \% \mathrm{MnZrO}_{2}$ & ethanol & 1 & $85-95$ & - & present work \\
\hline Lewis acid catalysts & ethanol & $1-14$ & 5-93 & - & 13 \\
\hline Heteropoly acids & acetic acid & 3 & $50-97$ & - & 15 \\
\hline Amberlite IR-120 & ethanol/water & $1.45-6.5$ & $70-95$ & - & 26 \\
\hline Polyaniline sulphate & $\mathrm{CH}_{2} \mathrm{Cl}_{2}$ & 2 & 90 & - & 27 \\
\hline $5 \% \mathrm{MnZrO}_{2}$ & ethanol & 1 & - & $85-93$ & present work \\
\hline MCM-41 & ethanol & 8 & - & $50-60$ & 28 \\
\hline $\mathrm{Ag}_{3} \mathrm{PW}_{12} \mathrm{O}_{40}$ & solvent free & $3-7$ & - & $72-90$ & 29 \\
\hline $\mathrm{NbCl}_{5}$ & $n$-hexane & $3-6$ & - & 85-95 & 30 \\
\hline $\mathrm{SbCl}_{3}-\mathrm{Al}_{2} \mathrm{O}_{3}$ & solvent free & $3-4$ & - & $83-90$ & 31 \\
\hline
\end{tabular}

dro-1H-1,5-benzodiazepine: yellow solid. mp: $149-151^{\circ} \mathrm{C}$; IR (KBr) 3349, 1643, $1593 \mathrm{~cm}^{-1}$. MS: $m / z=313\left(\mathrm{M}^{+}\right) .{ }^{1} \mathrm{H}$ NMR (300 Hz, DMSO): $\delta 1.72$ (s, 3H), 2.95 (d, 2H, $J=$ $0.17 \mathrm{~Hz}), 3.68$ (br, 1H), 6.93-7.79 (m, 14H).

\subsubsection{Comparison of catalytic activity of $\mathrm{MnZrO}_{2}-450$ catalyst with other reported catalysts}

A comparison of the catalytic activity of $\mathrm{MnZrO}_{2}-450$ in the synthesis of benzimidazole and benzodiazepines with those reported in the literature in terms of percentage yield of the respective products is given in the Table 5 .

\section{Conclusions}

The catalytic activity of alumina, zirconia, and manganese oxide supported on alumina and zirconia in the condensation reaction between OPDA and benzaldehyde/acetophenone is dependent on the amount of surface acid sites of the catalyst, which is influenced by a synergistic effect of the calcination, the presence of manganese oxide and the morphology of the catalysts. Manganese oxide supported on zirconia was found to be efficient heterogeneous catalyst for the synthesis of 2-substituted benzimidazoles and 1,5-disubstituted benzodiazepines by the condensation of $o$-phenylenediamine with different substituted aldehydes and ketones. Mild reaction conditions, easy work up, and high yields along with reusability of the catalyst make it a valuable alternative to the existing catalysts in the literature. The importance of the amount of surface acid sites and morphology of the catalysts in activating the condensation reaction between OPDA and an aldehyde/ketone is made clear.

\section{Acknowledgements}

We thank MRG at St. Joseph's College and Research Centre, Bangalore for helping us with XRD measurements. We also thank UGC, New Delhi for financial assistance.

\section{References}

1 Corma A. Chem Rev, 1995, 95: 559

2 Tanabe K, Misono M, Ono Y, Hattori H. New Solid Acids and Bases. Kodansha, Tokyo, 1989

3 Clark J H. Pure Appl Chem, 2001, 73: 103

4 Chen C, Chen Y. Tetrahedron Lett, 2004, 45: 113

5 Patil A, Ganguly S, Surana S. J Chem Sci, 2010, 122: 443

6 Valdez J, Cedillo R, Hernandez-Campos A, Yepez L, Hernandez-Luis F, Navarrete-Vazquez G, Tapia A, Cortes R, Hernandezc M, Castilloa R. Bioorg Med Chem Lett, 2002, 12: 2221

7 Fonseca T, Gigante B, Gilchrist T L. Tetrahedron, 2001, 57: 1793

8 Wang Y-C, Liu L-Z, Pan Y-M, Wang H-S. Molecules, 2011, 16: 100

9 Strenbach L H. J Med Chem, 1979, 22: 1

10 Schultz H. Benzodiazepines. Heidelberg: Springer, 1982

11 Randall L O, Kappel B, Garattini S, Mussini E, Randall L O eds. Benzodiazepines. New York: Raven Press, 1973. 27

12 Fryer R I. Bicyclic Diazepines. In: Taylor E C ed. Comprehensive Heterocyclic Chemistry. New York: Wiley, 1991. Volume 50, Chapter II

13 Zhang Z-H, Yin L, Wang Y-M. Catal Commun, 2007, 8: 1126

14 Mohammad A-A, Iraj M-B, Zaghaghi Z, Yousefi B H. Catal Commun, 2008, 9: 2496

15 Heravi M M, Sadjadi S, Oskooie H A, Shoar R H, Bamoharram F F. Catal Commun, 2008, 9: 504

16 Hekmatshoar R, Sajadi S, Heravi M M, Yahya S, Beheshtiha. Synth Commun, 2009, 39: 2549

17 Nagarapu L, Mallepalli R, Aravab G, Yeramanchi L. Eur J Chem, 2010, 3: 228

18 Kumar R, Chaudhary P, Nimesh S, Verma A K, Chandra R. Green Chem, 2006, 8: 519

19 Suryakiran N, Rajesh K, Prabhakara P, Jon Paul Selvam J, Venkateswarlu Y. Catal Commun, 2007, 8: 1635

20 Shanty M, Kumara C S, Nagaraju N. J Mol Catal A, 2006, 255: 243

21 Mohamed Shamshuddin S Z, Nagaraju N. J Mol Catal A, 2007, 273: 55 
22 Lee S O, Jung K H, Jung Oh C, Lee Y H, Tran T, Kim M J. Hydrometallurgy, 2009, 98: 156

23 Liu Y, Ma D, Han X, Bao X, Frandsen W, Wang D, Su D. Mater Lett, 2008, 62: 1297

24 Santos V, Zeni M, Bergmann C P, Hohemberger J M. Rev Adv Mater Sci, 2008, 17: 62

25 Breitkopf C, Garsuch A, Papp H. Appl Catal A, 2005, 296: 148

26 Ziarani G M, Badiei A, Abbasi A, Farahani Z. Chin J Chem 2009, 27: 1537
27 Srinivas U, Srinivas Ch, Narender P, Jayathirtha Rao V, Palaniappan S. Catal Commun, 2007, 8: 107

28 Sucheta K, Vital Rao B. Indian J Chem, 2005, 44B: 2152

29 Yadav J S, Reddy B V S, Kumar P S, Nagaiah K, Lingaiah N, Saiprasad P S. Synthesis, 2004, 6: 901

30 Gao S-T, Liu W-H, Ma J-J, Wang C, Liang Q. Synth Commun, 2009, 39: 3278

31 Ganai B A, Kumar S, Andotra C S, Kapoor K K. Synth Commun, 2006, 36: 803 